\title{
Optimization of Dyeing Time of Eco-friendly Cotton Coloration Using Banana (Musa Sapientum) Floral Stem Sap
}

\author{
Md. Reazuddin Repon ${ }^{1, *}$, Md. Abdullah Al Mamun', M Tauhidul Islam ${ }^{1,2}$ \\ ${ }^{1}$ Department of Textile Engineering, Mawlana Bhashani Science and Technology University, Bangladesh \\ ${ }^{2}$ Institute of Radiation and Polymer Technology, Bangladesh Atomic Energy Commission, Bangladesh
}

Copyright $\bigcirc 2016$ by authors, all rights reserved. Authors agree that this article remains permanently open access under the terms of the Creative Commons Attribution License 4.0 International License

\begin{abstract}
This study attempts to disclose the optimum dyeing time for exploiting banana agricultural bio-resource waste for sustainable dyeing of cotton fabric. $100 \%$ cotton knitted single jersey commercially scoured-bleached fabric used for this experiment having areal density 175 grams per square meter. Natural dye retrieved from banana floral stem by roller squeezer machine. Selected samples were dyed at $100^{\circ} \mathrm{C}$ for $20,30,40,50,60$ and 70 minutes respectively. Effect of time variation were calculated using CIE $\mathrm{L}^{*} \mathrm{a}{ }^{*} \mathrm{~b}^{*}$ color space in terms of colorimetric properties of colored fabric viz. color co-ordinates, color strength $(\mathrm{K} / \mathrm{S})$, brightness index (BI), degree of color levelness. Color fastness to wash, water, perspiration, rubbing and light were valued for estimating the color durability. Except light fastness property all tested color fastness properties were 3-5 i.e. very good to excellent. For all evaluated parameters samples dyed for 60 minutes exhibited best result. This reports forecast a sustainable technology for effective utilization banana floral stem sap bio-resource waste for coloration of cotton fabric.
\end{abstract}

Keywords Bio-resource Waste, Color Fastness, Eco-friendly, Banana, Natural Dye

\section{Introduction}

The art of coloration is our ancient advancement. From very old time till nineteenth century natural dyes were used just for textile coloration. Development and deployment of natural dyes for textile dyeing purposes had waned to a great extent after the familiarization of synthetic dyes for their better performance in terms of shade depth, ease of applicability, number of shades, color consistency, economy and wash durability on both the natural and man-made fibers.

Global market share of cotton is almost $48 \%$ as clothing materials. For complete processing of one kilogram cotton about 70 to150 liters fresh water is consumed [1]. Thus tremendous measure of colored harsh effluent are produced which engendering aquatic environment humiliation and several human diseases [2].

Researchers concluded sustainable textile processing could be possible either by using highly effluent treatment plant or eco-friendly dyes and chemicals [3]. For commercialization except natural dyeing, others sustainable method requires higher initial investment costs, highly sophisticated modern machinery, trained personnel, adequate research and so forth. So the use of cheap, non-allergic, non-carcinogenic, non-toxic, very brilliant, rare color idea and eco-friendly natural dyes on textiles is a re-emerged soaring interest around the globe. It is a potential viable 'Green chemistry' for avoiding the uses of hazardous synthetic dyes for their various growing environmental and health concerns [4-6].

Natural dyeing of cotton can be carried out by using numerous natural sources such as plants, insects/animals, microbes, minerals and renewable bio resource products. Among various sources banana is noteworthy due to vast availability. It is the fourth most vital worldwide nourishment ware after rice, wheat and maize as far as gross estimation of cultivation [7].

Banana plant has huge application in textile arena such as yarn, saree, shirt, female dress, night dress, coaster, table mat, stylish hand bag, eco-shopping bag, laminated fabric [8]. Additionally, banana plant parts also engaged with cotton coloration [9], mordant [10], functional finishing i.e. thermally stable cellulosic substrate [11] and dye adsorbent of textile effluent [12].

This current study attempts to develop a greener approach for coloration of cotton fabric by banana floral stem sap as natural dye for producing light shade. Moreover, aim of this work was effective exploitation of bio-resource waste of banana plant.

\section{Experimental}


Table 1. Whiteness Index (WI), Brightness Index (BI) and Color coordinate value of scoured-bleached sample

\begin{tabular}{|c|c|c|c|c|c|c|c|c|c|}
\hline WI & BI & $\mathrm{L}^{*}$ & $\mathrm{a}^{*}$ & $\mathrm{~b}^{*}$ & $\mathrm{c}^{*}$ & $\mathrm{H}$ & $\mathrm{R}$ & $\mathrm{G}$ & $\mathrm{B}$ \\
\hline 68.38 & 94.19 & 93.68 & -0.30 & 3.67 & 3.68 & 94.74 & 232 & 235 & 228 \\
\hline
\end{tabular}

\subsection{Materials and Methods}

\subsubsection{Materials}

Fabric used in this experiment includes commercially scoured-bleached $100 \%$ cotton knitted single jersey structure having areal density of 175 grams per square meter. Fabric was collected from "HI-FASHION COMPOSITE TEXTILES LTD”, Joydeppur, Gazipur, Bangladesh. One hundred percent cotton 22.7 tex combed yarn was used to manufacture the fabric. The fabric has the following geometrical properties: course per inch $(\mathrm{CPI})=48$, Wales per inch $(\mathrm{WPI})=37$, stitch length $=2.75 \mathrm{~mm}$. Following table 1 depicts the color co-ordinates of the fabric that used for this research work.

\subsubsection{Dyes \& Chemicals}

Banana floral Stem (Musa sapientum), which collected from Santosh, Tangail-1902, Bangladesh was used as natural dye. ISO Standard Soap, James heal, England had used for removing the unfixed dye from the surface of colored sample.

\subsection{Methods}

\subsubsection{Sampling}

Samples dyed for 20, 30, 40, 50, 60 and 70 minutes were identified as A, B, C, D, E and F respectively.

\subsubsection{Natural Dye Extraction}

Banana (Musa sapientum) floral stems were separated from banana tree and washed. Fresh floral stem of the banana was cut into one meter pieces using cutlass. Then the pieces were sliced. Sap extracted from floral stem by roller squeezer machine. Sap was filtrated by a nylon strainer and stored in plastic container. The saps were kept in a cool place and were prevented from sun rays to avoid evaporation and possible reaction for photo-catalytic degradation.

\subsubsection{Dyeing}

Dyeing had carried out according to exhaust method by Infra-red lab sample dyeing machine (XIAMEN RAPID, China) at $100^{\circ} \mathrm{C}$ for $20,30,40,50,60$ and 70 minutes respectively. Then the dye bath was cooled at $40^{\circ} \mathrm{C}$. Samples were washed at room temperature and air dried in flat dryer machine (MESDAN, Italy).Then soaping was performed for removing unfixed dye from the fabric surface by $0.5 \mathrm{~g} / \mathrm{L}$ ISO standard soap at $80^{\circ} \mathrm{C}$ for 10 minutes. For both dyeing and soaping, the material to liquor ration had kept 1:20.

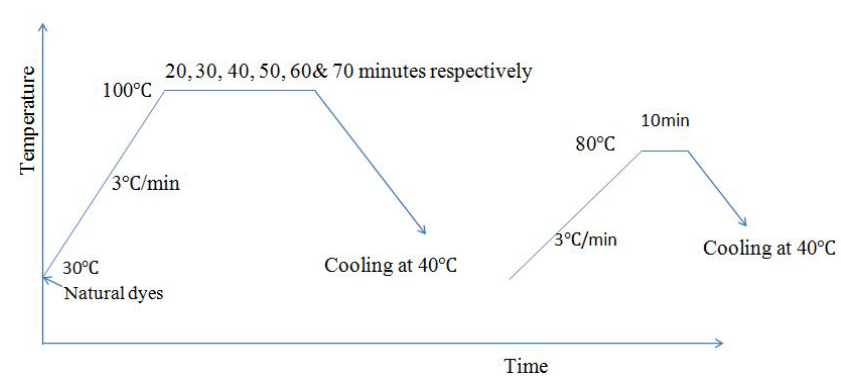

Figure 1. Dyeing Curve

\subsubsection{Determination of Color Coordinates Value}

The color coordinates of the dyed samples were determined based on the CIE Lab system via dual beam reflectance Data-color spectrophotometer, Spectroflash SF 650X, (Datacolor, USA) keeping the following setting: Illuminant D65, Medium area view, Specular included and CIE 1964 supple-mental standard observer ( $10^{\circ}$ observer). Each sample was folded twice to give an opaque view with four plies and the color coordinates value was measured automatically.

\subsubsection{Determination of Degree of Color Levelness}

Each dyed sample were measured using Data color spectrophotometer as above specified setting considering the reading-1 as standard and other nines as sample batches. Data for each batch are analyzed with respect to color difference, $\Delta \mathrm{E}$ value. $\Delta \mathrm{E}$ is a single value that takes into account the differences between the $L^{*}, a^{*}$ and $b^{*}$ values of the sample and standard in the CIE $\mathrm{L}^{*} \mathrm{a}^{*} \mathrm{~b}^{*}$ color system. The Eq. 1 was used to calculate the $\Delta \mathrm{E}$ [13].

$$
\Delta \mathrm{E}=\sqrt{ }\left\{\left(\Delta \mathrm{L}^{*}\right)^{2}+\left(\Delta \mathrm{a}^{*}\right)^{2}+\left(\Delta \mathrm{b}^{*}\right)^{2}\right\}
$$

$\Delta \mathrm{L}^{*}=\mathrm{L}^{*}$ sample $-\mathrm{L}^{*}$ standard, $\Delta \mathrm{a}^{*}=\mathrm{a}^{*}$ sample $-\mathrm{a}^{*}$ standard, $\Delta b^{*}=b^{*}$ sample $-b^{*}$ standard; where standard refers to the reading-1 in dyed fabric, sample refers to other readings in the corresponding dyed fabric. The $\Delta \mathrm{E}$ value is an important parameter in the dyeing process, which can indicate degree of levelness of dyed fabric. For the study, the degree of levelness was described according to $\Delta \mathrm{E}$ values [14] as shown in Table 2.

Table 2. Suggested interpretation of $\Delta \mathrm{E}$ values

\begin{tabular}{|l|l|l|}
\hline$\Delta \mathbf{E}$ values & $\begin{array}{c}\text { Visual appearance of } \\
\text { levelness }\end{array}$ & \multicolumn{1}{|c|}{ Extent of unlevelness } \\
\hline$\leq 0.20$ & Excellent levelness & Unlevelness not detectable \\
\hline $0.21-0.50$ & Good levelness & $\begin{array}{l}\text { Unlevelness noticeable under } \\
\text { close examination }\end{array}$ \\
\hline $0.51-1.0$ & Poor levelness & Apparent unlevelness \\
\hline$>1.0$ & Bad levelness & Conspicuous unlevelness \\
\hline
\end{tabular}




\subsubsection{Determination of Color Strength}

The color strength (K/S value) of the dyed samples was measured by datacolor spectrophotometer specified above, based on KubelkaMunk theory which give the relationship (Eq-2) between K/S and R as mentioned below [15].

$$
\mathrm{K} / \mathrm{S}=(1-\mathrm{R})^{2} / 2 \mathrm{R}
$$

Where, $\mathrm{R}$ is reflectance of an incident light from the dyed material, $\mathrm{K} \& \mathrm{~S}$ is absorption and scattering coefficient of the dyed fabric respectively. All the K/S values in this present study were determined at the maximum absorption wavelength $(? \max =360 \mathrm{~nm})$ at which reflectance value is lowest.

\subsubsection{Determination of Brightness Index}

Brightness index was measured as per the standard (ISO-2470-1977) [16] method using following relationship (Eq. 3) after measuring the reflectance value of the corresponding sample by Data color spectrophotometer according to above specified setting only specular excluded was set. Each sample was folded twice to give an opaque view with four plies and the reflectance value was measured automatically.

Brightness index $=$ Reflectance value of the substrate at 360 $\mathrm{nm} /$ Reflectance value of white diffuser or white tile at $360 \mathrm{~nm}$

\subsubsection{Determination of Color Fastness}

Standard methods were employed to evaluate various color fastness properties of the selected dyed fabric. Color fastness to wash, rubbing (dry and wet), light, water, perspiration was accessed by using grey scale of color change and staining according to ISO 105-C06:2010 [17], ISO-105x12:1995 [18], EN ISO 105-E01:2013 [19], ISO 105-E04:2013 [20] and EN ISO 105-B02: 2013 [21] correspondingly.

\section{Results and Discussion}

\subsection{Color Co-Ordinates Value of Dyed Samples}

Table 3 depicts the CIELAB color co-ordinates of dyed samples.
Table 3. Color co-ordinate

\begin{tabular}{|c|c|c|c|c|c|}
\hline \multirow{2}{*}{$\begin{array}{c}\text { Sample } \\
\text { types }\end{array}$} & \multicolumn{5}{|c|}{ Color co-ordinates } \\
\cline { 2 - 6 } & $\mathrm{L}^{*}$ & $\mathrm{a}^{*}$ & $\mathrm{~b}^{*}$ & $\mathrm{C}^{*}$ & $\mathrm{~h}^{0}$ \\
\hline $\mathrm{A}$ & 83.69 & 2.98 & 10.80 & 4.20 & 74.56 \\
\hline $\mathrm{B}$ & 83.72 & 2.81 & 9.87 & 10.26 & 74.10 \\
\hline $\mathrm{C}$ & 83.67 & 2.92 & 10.75 & 11.14 & 74.78 \\
\hline $\mathrm{D}$ & 82.43 & 3.14 & 10.63 & 11.09 & 73.56 \\
\hline $\mathrm{E}$ & 80.75 & 3.97 & 12.04 & 12.68 & 71.75 \\
\hline $\mathrm{F}$ & 82.18 & 3.07 & 10.78 & 11.27 & 72.81 \\
\hline
\end{tabular}

Regarding lightness $\left(\mathrm{L}^{*}\right)$, the samples orders were found as $\mathrm{B}>\mathrm{A}>\mathrm{C}>\mathrm{D}>\mathrm{F}>\mathrm{E}$. Minimum $\mathrm{L}^{*} 80.75$ was yield for $\mathrm{E}$ i.e. maximum darkness. Gradual increase of dyeing time has both positive and negative impact on color lightness. A, $\mathrm{B}, \mathrm{C}$ and $\mathrm{D}$ were $3.64 \%, 3.68 \%, 3.62 \%$ and $2.08 \%$ respectively lighter than E. Due to increase of dyeing time more dark shade was produced up to E. But F $1.77 \%$ lighter than E. Regarding redness $\left(a^{*}\right)$ orders of samples were found $\mathrm{E}>\mathrm{D}>\mathrm{F}>\mathrm{A}>\mathrm{C}>\mathrm{B}$. sample $\mathrm{E}$ were reddish amongst all. $\mathrm{A}, \mathrm{B}, \mathrm{C}, \mathrm{D}$ and $\mathrm{F}$ samples were $24.94 \%, 29.22 \%, 26.45 \%$, $20.91 \%$ and $22.67 \%$ greener than E. Concerning yellowness $\left(b^{*}\right)$ orders of samples were found $E>A>F>C>D>B$. Among them $\mathrm{E}$ showed maximum yellowness. $\mathrm{E}$ was $18.02 \%$ yellower than B. A, C, D and F samples were $10.3 \%, 10.71 \%, 11.71 \%$ and $10.47 \%$ bluer than $\mathrm{E}$ respectively. The orders color saturation $\left(\mathrm{c}^{*}\right)$ of samples were found to be $\mathrm{E}>\mathrm{F}>\mathrm{C}>\mathrm{D}>\mathrm{B}>\mathrm{A}$. E had highest color saturation among all samples. $\mathrm{E}$ was $66.88 \%$ more saturated with color than A. Sample B, C, D and F was $19.09 \%$, $12.15 \%, 12.54 \%$ and $11.12 \%$ low color saturation than $\mathrm{E}$ correspondingly. For hue angle $\left(h^{0}\right)$ orders of samples were found $\mathrm{C}>\mathrm{A}>\mathrm{B}>\mathrm{D}>\mathrm{F}>\mathrm{E}$. For $\mathrm{C}$ hue angle was highest. The highest $4.05 \%$ hue angle decreased for $\mathrm{E}$ than $\mathrm{C}$. The hue angle of sample A, B, D and F were $3.92 \%, 3.28 \%, 2.52 \%$ and $1.48 \%$ more than $\mathrm{E}$ respectively.

\subsection{Degree of Color Levelness}

The orders average color difference value of samples were found $\mathrm{D}>\mathrm{A}>\mathrm{F}>\mathrm{B}>\mathrm{C}>\mathrm{E}$ (Table 4). Lowest $\Delta \mathrm{E}$ value i.e. excellent levelness of color levelness was yield for $\mathrm{E}$. The color of sample E was $81.16 \%$ more level than sample D. Though, there was difference in average color difference value but all samples showed excellent color levelness.

Table 4. Degree of color levelness.

\begin{tabular}{|c|c|c|c|c|c|c|c|c|c|c|c|}
\hline \multirow{3}{*}{$\begin{array}{l}\text { Sample } \\
\text { types }\end{array}$} & \multicolumn{10}{|c|}{$\Delta \mathrm{E}$ values of dyed samples } & \multirow{3}{*}{ Average $\Delta \mathrm{E}$} \\
\hline & \multirow{2}{*}{$\mathrm{R}-1$} & $\mathrm{R}-2$ & $\mathrm{R}-3$ & $\mathrm{R}-4$ & $\mathrm{R}-5$ & $\mathrm{R}-6$ & $\mathrm{R}-7$ & $\mathrm{R}-8$ & R-9 & $\mathrm{R}-10$ & \\
\hline & & \multicolumn{9}{|c|}{ Batch readings } & \\
\hline A & \multirow{6}{*}{ 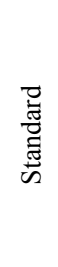 } & 0.274 & 0.101 & 0.266 & 0.073 & 0.163 & 0.057 & 0.070 & 0.059 & 0.027 & 0.121 \\
\hline $\mathrm{B}$ & & 0.208 & 0.228 & 0.076 & 0.062 & 0.086 & 0.109 & 0.102 & 0.030 & 0.033 & 0.104 \\
\hline $\mathrm{C}$ & & 0.271 & 0.171 & 0.154 & 0.042 & 0.092 & 0.021 & 0.051 & 0.031 & 0.040 & 0.097 \\
\hline $\mathrm{D}$ & & 0.502 & 0.205 & 0.185 & 0.017 & 0.040 & 0.064 & 0.019 & 0.067 & 0.027 & 0.125 \\
\hline $\mathrm{E}$ & & 0.292 & 0.038 & 0.067 & 0.029 & 0.072 & 0.047 & 0.048 & 0.017 & 0.014 & 0.069 \\
\hline $\mathrm{F}$ & & 0.333 & 0.122 & 0.155 & 0.021 & 0.097 & 0.052 & 0.151 & 0.092 & 0.026 & 0.117 \\
\hline
\end{tabular}




\subsection{Color Strength $(K / S)$ Value}

The figure 2 illustrates the effect of time variation on the dye fixation of dyed materials. The color strength value of samples were found $\mathrm{E}>\mathrm{F}>\mathrm{D}>\mathrm{B}>\mathrm{C}>\mathrm{A}$ orderly. The maximum color strength 0.65 is yield for $\mathrm{E}$ at wavelength $360 \mathrm{~nm}$. The $\mathrm{K} / \mathrm{S}$ value of $\mathrm{A}, \mathrm{B}, \mathrm{C}, \mathrm{D}$ and $\mathrm{F}$ samples were $29.23 \%, 24.62 \%, 27.69 \%, 20 \%$ and $16.92 \%$ lower than E.

\subsection{Brightness Index Value}

The figure 3 depicts the effect of time variation on brightness index of the sample. Regarding brightness index value, the samples orders were found as $\mathrm{A}>\mathrm{C}>\mathrm{F}>\mathrm{B}>\mathrm{D}>\mathrm{E}$. Time variation has positive and negative impact on brightness index value. The highest brightness index value were 60.71 for A and lowest value 58.50 for E. The samples A, B, C, D and F showed 3.78\%, 2.82\%, 3.40\%, $0.36 \%$ and $2.91 \%$ more bright than $\mathrm{E}$.

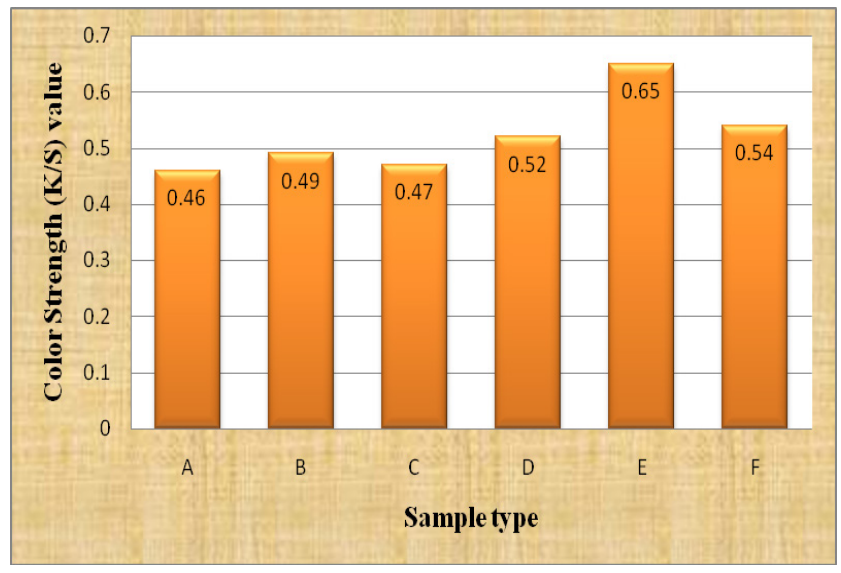

Figure 2. Color Strength $(\mathrm{K} / \mathrm{S})$ value

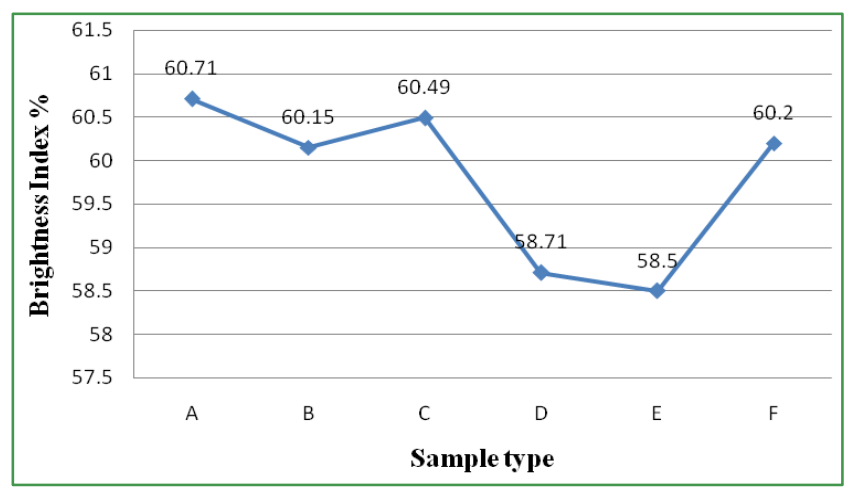

Figure 3. Brightness index\% value

\subsection{Color Fastness to Wash}

Table 5 presents the color fastness to wash. The overall results of color fastness to wash of samples were very good to excellent.

A and B were showed very good result in color change and color staining on cotton and wool. But the results of all other samples in color change and staining on multifibre exhibited excellent grade.

\subsection{Color Fastness to Rubbing and Light}

The grade of color fastness to rubbing and light of the samples were evaluated that presents in the Table 6 . The overall results of color fastness to rubbing of samples were good to excellent. Wet rubbing properties were lower than dry rubbing. A, B, C and F were exhibited good wet rubbing and excellent dry rubbing properties. D and $\mathrm{E}$ showed excellent rubbing properties in both cases.

Unfortunately, the samples A, B, C and F showed poor light fastness properties i.e. 2 where $\mathrm{D}$ and $\mathrm{E}$ showed a little bit improved grade i.e. 2-3.

Table 5. Color fastness to wash

\begin{tabular}{|c|c|c|c|c|c|c|c|}
\hline \multirow{2}{*}{ Samples types } & \multirow{2}{*}{$\begin{array}{c}\text { Change in } \\
\text { Color }\end{array}$} & \multicolumn{6}{|c|}{ Staining in Color } \\
\cline { 3 - 8 } & & Acetate & Cotton & Nylon & Polyester & Acrylic & Wool \\
\hline A & 4 & $4-5$ & 4 & $4-5$ & $4-5$ & $4-5$ & $3-4$ \\
\hline B & 4 & $4-5$ & 4 & $4-5$ & $4-5$ & $4-5$ & $3-4$ \\
\hline C & $4-5$ & $4-5$ & $4-5$ & $4-5$ & $4-5$ & $4-5$ & $4-5$ \\
\hline D & $4-5$ & $4-5$ & $4-5$ & $4-5$ & $4-5$ & $4-5$ & $4-5$ \\
\hline E & $4-5$ & $4-5$ & $4-5$ & $4-5$ & $4-5$ & $4-5$ & $4-5$ \\
\hline F & $4-5$ & $4-5$ & $4-5$ & $4-5$ & $4-5$ & $4-5$ & $4-5$ \\
\hline
\end{tabular}

Table 6. Color fastness to rubbing and light fastness properties

\begin{tabular}{|c|c|c|c|}
\hline \multirow{2}{*}{ Samples types } & \multicolumn{2}{|c|}{ Rubbing fastness } & \multirow{2}{*}{ Light fastness } \\
\cline { 2 - 4 } & Dry rubbing & Wet rubbing & 2 \\
\hline A & $4-5$ & 3 & 2 \\
\hline B & $4-5$ & $3-4$ & 2 \\
\hline C & $4-5$ & $3-4$ & $2-3$ \\
\hline D & $4-5$ & $4-5$ & $2-3$ \\
\hline F & $4-5$ & $4-5$ & 2 \\
\hline
\end{tabular}


Table 7. Color fastness to water

\begin{tabular}{|c|c|c|c|c|c|c|c|}
\hline \multirow{2}{*}{ Samples types } & \multirow{2}{*}{$\begin{array}{c}\text { Change in } \\
\text { Color }\end{array}$} & \multicolumn{6}{|c|}{ Staining in Color } \\
\cline { 3 - 9 } & & Acetate & Cotton & Nylon & Polyester & Acrylic & Wool \\
\hline A & 4 & $4-5$ & 4 & $4-5$ & $4-5$ & $4-5$ & $3-4$ \\
\hline B & $3-4$ & $4-5$ & 4 & $4-5$ & $4-5$ & $4-5$ & 4 \\
\hline C & $4-5$ & $4-5$ & $4-5$ & $4-5$ & $4-5$ & $4-5$ & $4-5$ \\
\hline D & $4-5$ & $4-5$ & $4-5$ & $4-5$ & $4-5$ & $4-5$ & $4-5$ \\
\hline E & $4-5$ & $4-5$ & $4-5$ & $4-5$ & $4-5$ & $4-5$ & $4-5$ \\
\hline F & $4-5$ & $4-5$ & $4-5$ & $4-5$ & $4-5$ & $4-5$ & $4-5$ \\
\hline
\end{tabular}

Table 8. Color fastness to perspiration

\begin{tabular}{|c|c|c|c|c|}
\hline \multirow{2}{*}{ Samples types } & \multicolumn{2}{|c|}{ Alkaline } & \multicolumn{2}{|c|}{ Acid } \\
\cline { 2 - 5 } & Change in Color & Color Staining on Cotton & Change in color & Color Staining on Cotton \\
\hline A & $4-5$ & $4-5$ & $3-4$ & 4 \\
\hline B & $4-5$ & $4-5$ & $4-5$ & $4-5$ \\
\hline C & $4-5$ & $4-5$ & $4-5$ & $4-5$ \\
\hline D & $4-5$ & $4-5$ & $4-5$ & $4-5$ \\
\hline E & $4-5$ & $4-5$ & $4-5$ & $4-5$ \\
\hline F & $4-5$ & $4-5$ & $4-5$ & $4-5$ \\
\hline
\end{tabular}

\subsection{Color Fastness to Water}

Table 7 illustrates the grading of color fastness to water. The overall results of all samples were showed very good to excellent.

A showed color change grading 4 and others were excellent grading. Staining in color onto cotton and wool is very good for A and B samples. Staining on others multifibre fabric exhibited excellent grade for all other samples.

\subsection{Color Fastness to Perspiration}

Table 8 illustrates the evaluation of fastness to perspiration. The overall results of color fastness to perspiration of samples in both alkaline and acidic medium were very good to excellent.

In alkaline perspiration, color change and color staining on cotton for all samples showed excellent grade i.e. 4-5. Expediently, A showed very good color change and staining on cotton in acid where as other samples excellent result.

\section{Conclusions}

This study is a new approach for textile coloration using green chemistry using banana bio-resources waste. Cotton knitted fabric dyed with banana floral stem sap produced light shade. Slightly deep shade was produced with increasing dyeing time. Though, dye fixation rate increase with the increasing of dyeing time but it decreased for 70 minutes. From measured value of colorimetric and Color fastness it is concluded that the best result was obtained for 60 minutes. So, the optimum dyeing time is 60 minutes for cotton coloration with banana floral stem sap. This coloration process can be used where light fastness is not so important. Further study can be carried out to improve it's light fastness and producing dark shade.

\section{REFERENCE}

[1] Bhuiyan M. R., Rahman, M.M. Shaid A. and Khan M.A., "Application of gamma irradiated textile wastewater for the pretreatment of cotton fabric". Environment and Ecology Research, vol.2 No.3, pp.149-152, 2014.

[2] Forgacs E, Cserháti T, Oros G. "Removal of synthetic dyes from wastewaters: a review". Environment International; vol.30, No.7, pp. 953- 971, 2004.

[3] Rajendran R, Balakumar C, Kalaivani T, Sivakumar R, "Dyeability and antimicrobial properties of the cotton fabrics finished with Punica Granatum extracts". J Text Apparel Technol Manage, Vol. 7, pp.1-12, 2011.

[4] Bechtold T., Turcanu A., Ganglberger E., Geissler, S., "Natural dyes in modern textile dyehouse - how to combine experiences of two centuries to meet demands of the future?" J. Clean. Prod. Vol.11, pp.499-509, 2003.

[5] Salah M. Saleh, Yasser A. Abd-El-Hady, Kh. El-Badry, "Eco-friendly Dyeing of Cotton Fabric with Natural Colorants Extracted from Banana Leaves". International Journal of Textile Science, Vol. 2, No.2, pp. 21-25, 2013.

[6] Kh. EL-Nagara and Mamdouh Halawa. "Effect of mordant types on electrical measurements of cotton fabric dyed with onion scale natural dye". Ijeet. Vol 3, No.2, pp.192-203, 2012.

[7] Shyamala Bellur, Nagarajaiah and Jamuna Prakash, "Chemical composition and antioxidant potential of peels 
from three varieties of banana". Asian Journal of Food and Agro-Industry; Vol 4, No 01; pp. 31-46, 2011.

[8] Kumar Sampath K. P., Bhowmik Debjit, Duraivel S., Umadevi M., "Traditional and Medicinal Uses of Banana". Journal of Pharmacognosy and Phytochemistry; Vol 1; No. 3; pp. 51-63, 2012.

[9] Dzomeku B. M. and Boateng O. K., "Exploring the Potential of Banana Sap as Dye for the Adinkra industry in Ghana". International Journal of Bio-resource and Stress Management; Vol. 4, No.2, pp. 378-381,2013.

[10] Paul V., Kanny K., Redhi G.G., "Formulation of a novel bio-resin from banana sap". Industrial Crops and Products; Vol 43; pp. 496- 505, 2013.

[11] Samanta, A.K., Agarwal, P. "Application of natural dyes on textiles”. Indian J. Fibre Text. Res.; Vol. 34; pp. 384-399, 2009.

[12] Shuaibing, Z.M.Z.S.L. and Qihua, Z., "Adsorption of dye wastewater by banana peel powder immobilized by sodium alginate". Chinese Journal of Environmental Engineering, Vol.6, p.036, 2013
[13] Millward S, "Color difference equations and their assessment”. Test Target J 9:19-26, 2009.

[14] Mohammad Gias Uddin, "Extraction of eco-friendly natural dyes from mango leaves and their application on silk fabric". Textiles and Clothing Sustainability, Vol.1, No.7, 2015.

[15] Mcdonald, R (Ed.). (1997). Color physics for industry (2nd ed.). Soc. Bradford: Dyers and Colorist

[16] Paper and board: Measurement of diffused blue reflectance factor (ISO-brightness) ISO $2469 \& 2470,2$ nd (International Prganization for Standaradization Switzerland), 1977,1

[17] AATCC.2013. AATCC Test Method 61-2013 Colorfastness to Laundering: Accelerated

[18] AATCC. 2013. AATCC Test Method 8-2013 Colorfastness to Rubbing

[19] AATCC. 1996. AATCC Test Method 125-2013 Colorfastness to light

[20] AATCC. 2008. AATCC Test Method 107-2013 Colorfastness to Water

[21] AATCC. 2006. AATCC Test Method 15-2013 C 